\title{
Opportunistic Infections in Renal Transplantation -A Case Series
}

\author{
Rita Sampaio ${ }^{*}$, José Palla Garcia1, Leonídio Dias², La Salete Martins², José Ramón Vizcaíno1 \\ ${ }^{1}$ Department of Pathology, Hospital de Santo António, Centro Hospitalar do Porto, Porto, Portugal \\ ${ }^{2}$ Department of Nephrology, Hospital de Santo António, Centro Hospitalar do Porto, Porto, Portugal \\ Email: *ritabsampaio7@gmail.com
}

How to cite this paper: Sampaio, R., Garcia, J.P., Dias, L., Martins, L.S. and Vizcaíno, J.R. (2017) Opportunistic Infections in Renal Transplantation-A Case Series. Open Journal of Pathology, 7, 13-19. http://dx.doi.org/10.4236/ojpathology.2017. $\underline{71002}$

Received: October 25, 2016

Accepted: January 1, 2017

Published: January 4, 2017

Copyright (C) 2017 by authors and Scientific Research Publishing Inc. This work is licensed under the Creative Commons Attribution International License (CC BY 4.0).

http://creativecommons.org/licenses/by/4.0/

\begin{abstract}
Background: Porto's Hospital Centre is one of the most active Portuguese hospitals in renal transplantation (performed since 1983). Although increasingly rare, opportunistic infections in transplanted patients are associated with high mortality rate in kidney transplantation and remain a major diagnostic challenge. Methods: We investigated 2041 cases of hospital admissions (from 2004 to 2012), any time after kidney transplantation. We described the infection location, the diagnostic techniques used and the mortality after the infection. Results: We found 82 cases of opportunistic infection caused by Herpes virus (Zoster and simplex), Cytomegalovirus, Polyomavirus, Aspergilus, Alternaria, Mucorales, Candida, Mycobacterium tuberculosis, Cryptococcus and Pneumocystis. Conclusions: In this article we highlight the important role of histology/cytology in the diagnostic process of these infections. In many cases prompt diagnosis and treatment are necessary to avoid life-threatening complications and may greatly improve prognosis.
\end{abstract}

\section{Keywords}

Transplant Pathology, Kidney, Opportunistic Infections

\section{Introduction}

Kidney transplantation is acknowledged as a major advance of modern medicine, providing high-quality life years for patients with end-stage kidney disease [1].

Infections agents can often be recognized on the basis of the time interval from transplantation, however they are still a common cause of morbidity and mortality after the transplant.

A successful kidney transplant increases the lifespan, quality of life and it is more effective economically than long term dialysis therapy [2].

The first month after transplantation is dominated by infections related to the surgical procedure, including urinary tract infection (Escherichia coli), line infection (Sta- 
phylococcus aureus and Streptococci viridans), wound infection (Staphylococcus aureus and Streptococci viridans) and pneumonia (Streptococcus pneumonia).

The period between the first and sixth months is associated with the highest levels of immunosuppression and thus the greatest risk of opportunistic infections.

Herpes virus may be transmitted through the transplanted organ or may be reactivated because of the immunosuppressive drugs [3].

BK virus is the most frequent pathogenic agent of polyomavirus nephropathy in kidney recipients and like Herpes virus, is commonly reactivated under immunosuppression because after infection that often is acquired in childhood it persists in urothelium of healthy individuals [4].

Cytomegalovirus (CMV) belong to the viral family Herpesviridae and it is one of the most common opportunistic viral pathogens in renal recipients, affecting about $60 \%$ of patients but only $20 \%$ will develop symptomatic disease [5].

Invasive fungal infections are a lethal problem in transplant patients. Infections caused by Aspergillus species, Mucorales species, Candida species, Pneumocystis and Cryptococcus neoformans are the opportunistic fungi responsible for most of such infections [6].

Alternaria are ubiquitous dematiaceous fungi, that rarely affected healthy hosts, but can be fatal for patients that underwent large periods of immunosuppression as some cases of kidney transplant [7]. Kidney recipients have a major risk of developing tuberculosis, especially if they are living in endemic areas or have a latent infection [8].

\section{Objectives}

The aim of this study was to evaluate the incidence of opportunistic infection (OI) in renal transplant patients, admitted in Nephrology Department (which has approximately 600 admissions per year), in our Central and University Hospital. We also identified the location of the infection, the corresponding techniques of diagnosis used and the mortality rate after the infection.

\section{Methods}

In order to fulfill the purpose of this study, a retrospective investigation was carried out using the Nephrology Department's general database and found transplanted patients who have undergone hospital admission any time after renal transplant. We consulted registries from 2004 to 2012 to identify the patients stricken by OI, using it as inclusion criteria in the study population. The cases with missing or inconclusive clinical data were excluded from the study. Sequentially, to investigate the history of each patient and obtain the information mentioned above, we consulted the hospital computerized system called SAM (Medical Support Service) collected the age, gender, serology, molecular biology, cultures, cytology and histology results, when performed. In cases with histologic and cytologic diagnosis, reports were found in pathology computerizes system called Citopro and slides were raised and revised.

\section{Results}

We investigated a total of 2041 cases of hospital admission and found 82 cases of OI 
that led to hospital admission and were caused by Herpes virus (zoster and simplex), CMV, Polyomavirus, Aspergillus, Alternaria, Mucorales, Candida, Mycobacterium tuberculosis, Cryptococcus and Pneumocystis. The lung and urogenital system were the most affected systems. Kidneys were affected in 3 cases by mucormycosis, tuberculosis and Cryptococcus. Skin was affected by herpes zoster and Alternaria. From all cases of OI, 42 were diagnosed by Department of Anatomic Pathology (19 through biopsy; 23 through cytology; 2 of them through biopsy and cytology) (Table 1).

\section{Discussion}

Accordingly with other studies, among the viral pathogens identified, CMV has the greatest incidence, followed by polyomavirus and Herpes zoster. The complementary means of diagnosis used to identify CMV and Herpes zoster were made by serology and molecular biology in blood samples. The cases of CMV diagnosed through biopsy/histology corresponded to gastrointestinal involvement and three cases diagnosed through cytology corresponded to lung affected cases (Table 1). In our population, polyomavirus has affected exclusively the genitourinary tract and could be diagnosed via histology and cytology (Figure 1, Figure 2), with characteristic images. In third place of incidence was Candida affecting mainly genitourinary tract. In others studies Candida, Aspergillus and Pneumocystis had instead the major incidences. The cases of aspergilosis, alternaria, mucormycosis and in some cases of tuberculosis the diagnosis were executed through histology or cytology techniques due to culture difficulty. The fourth place in our study belongs to tuberculosis (Figure 3), revealing a high

Table 1. Opportunistic infections, affected organs and diagnostic techniques.

\begin{tabular}{|c|c|c|c|c|c|c|c|c|c|c|c|c|c|c|c|c|c|c|c|c|}
\hline & \multicolumn{14}{|c|}{ Affected Organs } & \multicolumn{6}{|c|}{ Diagnostic techniques } \\
\hline & 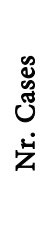 & 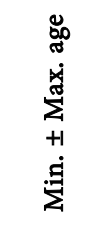 & 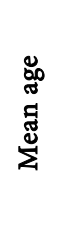 & $\sum_{\infty}^{\mathbb{S}}$ & 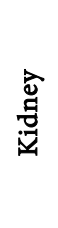 & 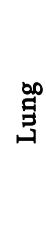 & 紊 & 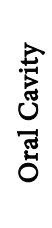 & 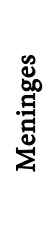 & 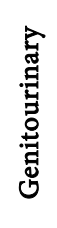 & 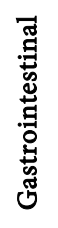 & 范 & 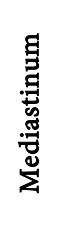 & ‡్ & 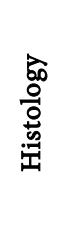 & 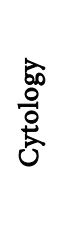 & 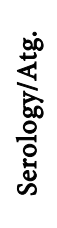 & 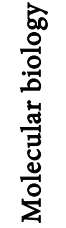 & 苞 & 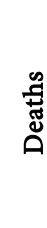 \\
\hline Herpes zoster & 7 & $29 \pm 69$ & 50 & 43 & - & - & 7 & 7 & - & - & - & - & - & - & - & - & 7 & - & - & 1 \\
\hline Cytomegalovirus & 27 & $23 \pm 69$ & 41 & 44 & - & 3 & - & - & - & - & 2 & - & - & - & 2 & 3 & 27 & 2 & - & 3 \\
\hline Polyomavirus & 16 & $24 \pm 56$ & 37 & 63 & - & - & - & - & - & 16 & - & - & - & - & 2 & 8 & - & 16 & - & 4 \\
\hline Aspergillus & 4 & $36 \pm 63$ & 54 & 75 & - & 4 & - & - & - & - & - & - & - & - & 3 & 3 & - & - & - & 1 \\
\hline Alternaria & 2 & $52 \pm 60$ & 56 & 50 & - & - & 2 & 2 & - & - & - & - & - & - & 2 & - & - & - & - & 1 \\
\hline Mucorales & 1 & 64 & 64 & 100 & 1 & - & - & - & - & - & - & - & - & - & 1 & - & - & - & 1 & 1 \\
\hline Candida & 12 & $26 \pm 80$ & 48 & 17 & - & 3 & - & - & - & 6 & - & - & - & - & 2 & 7 & - & - & 5 & 1 \\
\hline Mycobacterium tubeculosis & 9 & $32 \pm 53$ & 41 & 67 & $1^{*}$ & 6 & - & - & - & 1 & 2 & $1^{*}$ & $1^{\star}$ & $1^{*}$ & 6 & 2 & - & 3 & 6 & 3 \\
\hline Cryptococcus & 2 & $34 \pm 57$ & 46 & 100 & 1 & 2 & - & - & 1 & - & - & - & - & - & 1 & - & - & 1 & 1 & - \\
\hline Pneumocistis & 2 & $60 \pm 54$ & 57 & 100 & - & 2 & - & - & - & - & - & - & - & - & - & - & - & - & - & 2 \\
\hline Total & 82 & $23 \pm 80$ & & 51 & 3 & 20 & 9 & 9 & 1 & 23 & 4 & 1 & 1 & 1 & 19 & 23 & 34 & 22 & 13 & 17 \\
\hline
\end{tabular}

Min., minimum; Max., maximum. Atg, antigens. ${ }^{*}$ Corresponding to the same case. 


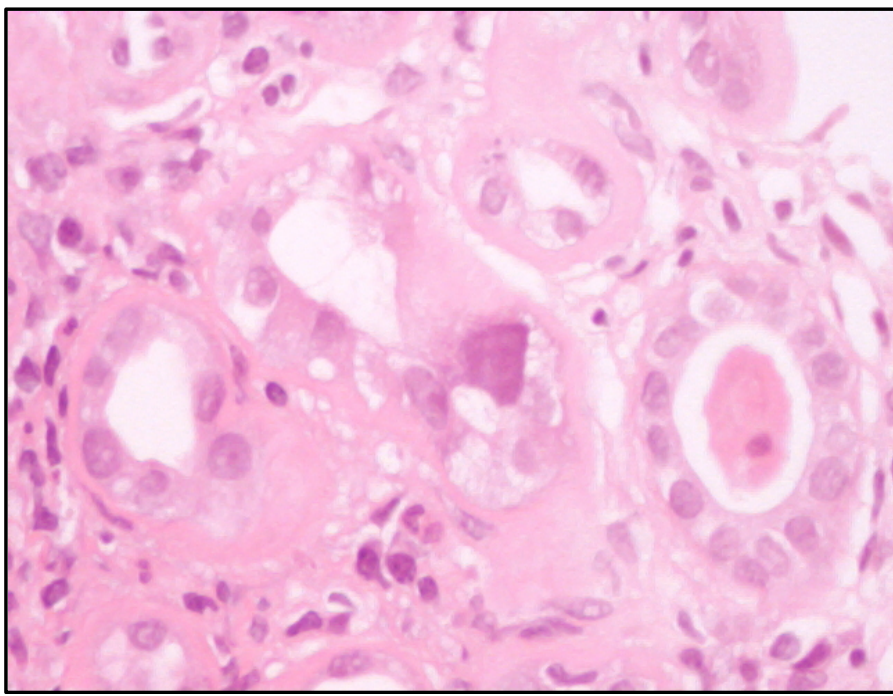

Figure 1. Polyomavirus kidney-biopsy (HE 400×).

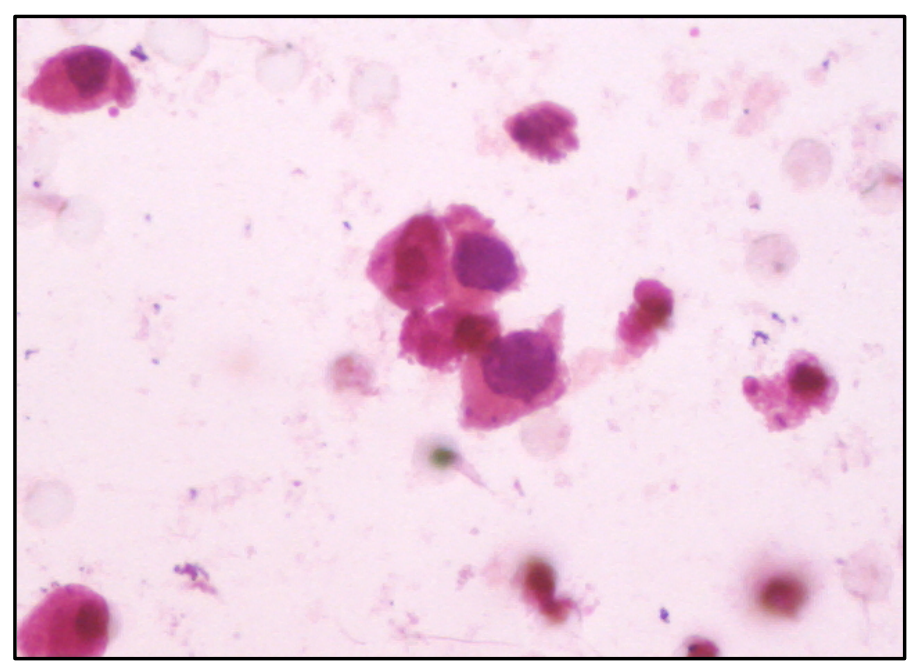

Figure 2. Polyomavirus-urinary cytology (400×).

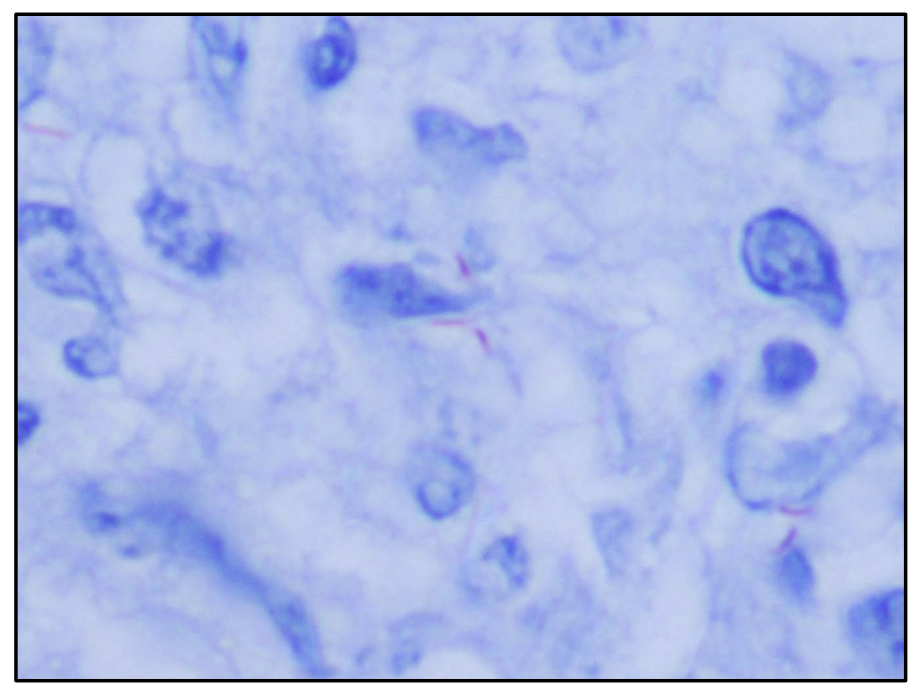

Figure 3. Tuberculosis larynx-biopsy (Ziehl Neelsen 400×). 
incidence compared with other studies, probably because this disease is still endemic in Portugal.

Deaths that occurred during the admissions episode were related with patient morbidities. There were eight deaths diretly related to OI and the responsible microorganisms were Aspergillus, Alternaria, Mucorales, Mycobacterium tuberculosis, Cryptococcus and Pneumocystis.

The histological features of Aspergillus are a non pigmented septate microorganisms

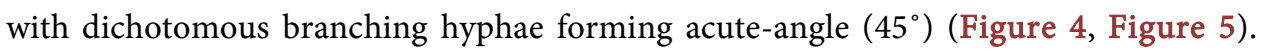
Alternaria shows pigmented hyphae and round-shaped fungal cells in a granulomatous dermal infiltrate (Figure 6). Mucorales is a hyaline, thin walled, pauciseptate hyphae with right angle branching (Figure 7). Cryptococcus are a narrow-based budding yeasts with a thick capsule (Figure 8). Pneumocystiis are a small yeasts with narrow based budding grouped in clusters.

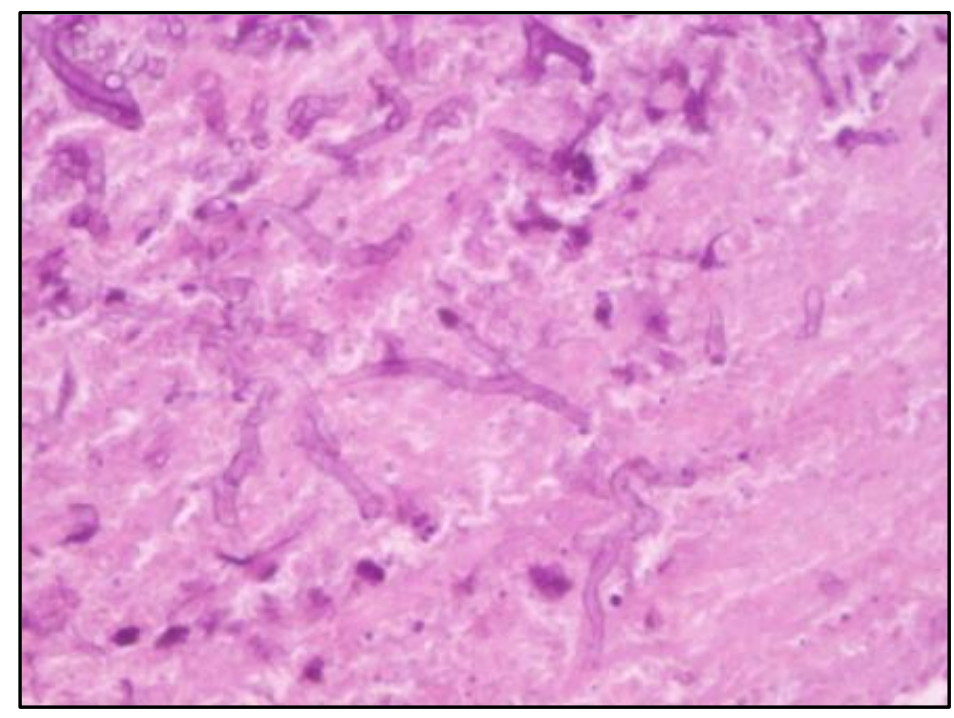

Figure 4. Aspergillus lung-biopsy (HE 400×).

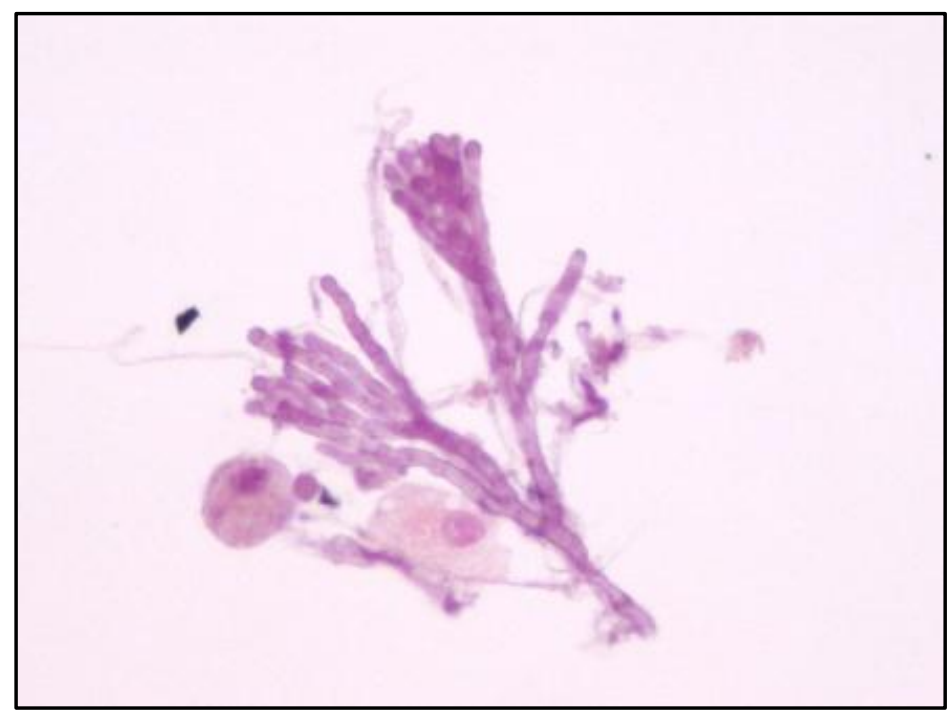

Figure 5. Aspergillus lung-cytology (20x). 


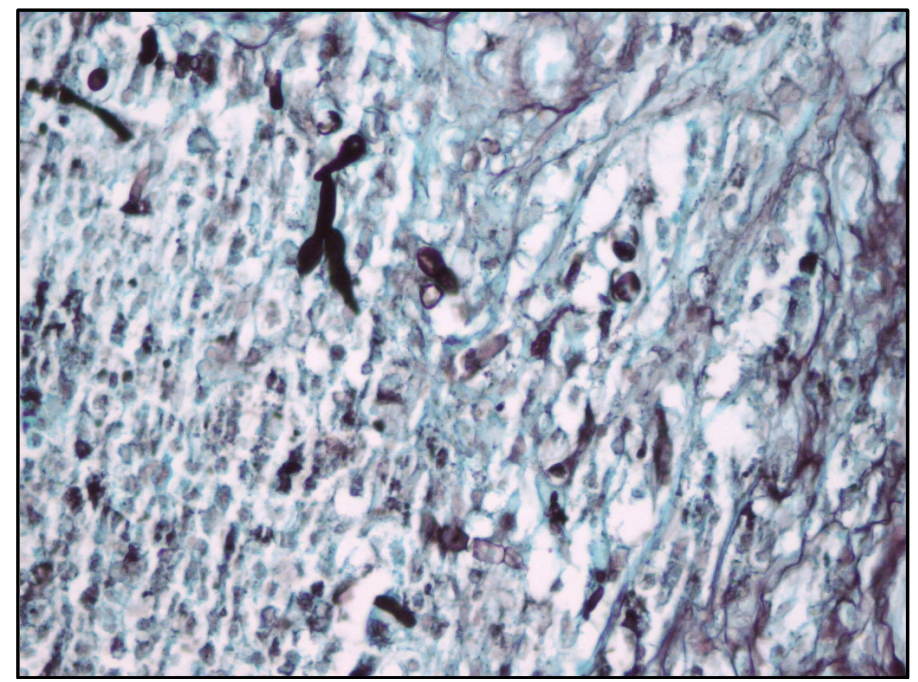

Figure 6. Alternaria skin-biopsy (Grocott 400×).

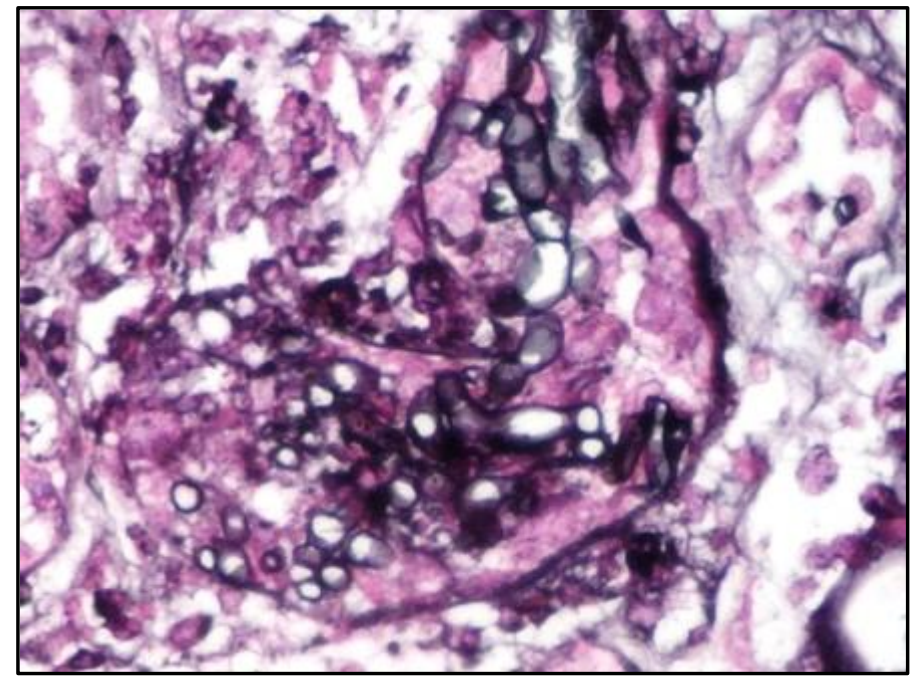

Figure 7. Mucorales kidney-biopsy (Silver 400×).

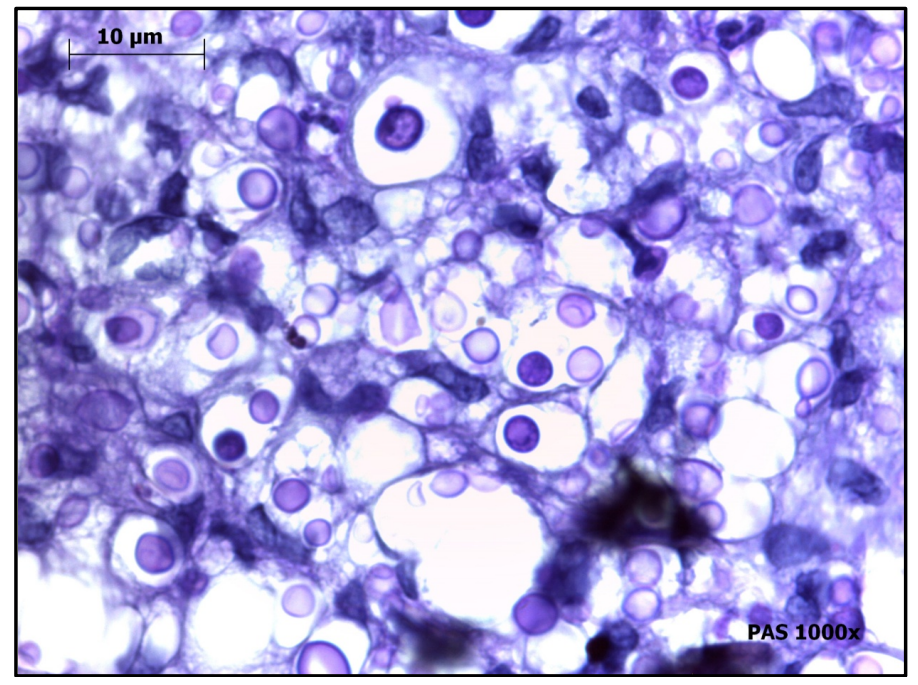

Figure 8. Cryptococcus kidney-biopsy (PAS 1000×). 


\section{Conclusion}

The increased use of the anatomic pathology as diagnostic method is explained because it is a practical and sensitive screening method and also because it allows a rapid detection. Furthermore, culture as a method of diagnosis is not always sensitive, does not always discriminate between invasive disease, colonization and contamination and also usually takes more than a week to appropriate fungal growth to occur. Serologic diagnosis is not normally suitable in immunosuppressed patients, because antibody production is slowed. Molecular methods, in spite of being potentially more sensitive and a faster method of diagnosis, are not universally standardized and their specificity and sensitivity vary in different studies. Therefore, the cytology and histology should be viewed most of times as a first way of prompt diagnosis in these patients.

\section{References}

[1] Garcia, G.G., Harden, P. and Chapman, J. (2012) The Global Role of Kidney Transplantation. Current Opinion in Nephrology and Hypertension, 3, 229-234. https://doi.org/10.1097/MNH.0b013e328352586d

[2] Tonelli, M., Wiebe, N., Knoll, G., Bello, A., Browne, S., Jadhav, D., Klarenbach, S. and Gill, J. (2011) Systematic Review: Kidney Transplantation Compared With Dialysis in Clinically Relevant Outcomes. American Journal of Transplantation, 11, 2093-2109. https://doi.org/10.1111/j.1600-6143.2011.03686.x

[3] Morrone, L.F., Capurso, D., D’Elia, F., Di Paolo, S., Grandaliano, G., Marangi, A.L., Schena, A., Stallone, G. and Tarantino, G. (2002) Herpetic Viruses and Renal Transplantation. Giornale Italiano Di Nefrologia, 19, 316-325.

[4] Bröcker, V., Schwarz, A. and Becker, J.U. (2011) BK Virus Nephropathy after Kidney Transplantation. Pathologe, 32, 399-405.

[5] Cordero, E., Casasola, C., Ecarma, R. and Danguilan, R. (2012) Cytomegalovirus Disease in Kidney Transplant Recipients: Incidence, Clinical Profile, and Risk Factos. Transplantation Proceedings, 44, 694-700. https://doi.org/10.1016/j.transproceed.2011.11.053

[6] Badiee, P. and Alborzi, A. (2011) Invasive Fungal Infections in Renal Transplant Recipientes. Experimental and Clinical Transplantation, 9, 355-362.

[7] Ara, M., Aspiroz, C., Zaballos, P., Alcalde, V., Alvarez, R., Rezusta, A. and Giménez, J.A. (2006) Relapse of Cutaneous Alternaria Infectoria in a Renal Transplant Recipient after 2 Years. Acta Dermato-Venereologica, 86, 154-155.

[8] Rosado Rubio, C., García Cosmes, P., Fraile Gómez, P., Valverde Martínez, S., Díez Bandera, R., González Álvarez, C. and Iglesias Gómez, A. (2011) Atypical Localization of Tuberculosis in Kidney Transplants. Nefrologia, 31, 622-624. 
Submit or recommend next manuscript to SCIRP and we will provide best service for you:

Accepting pre-submission inquiries through Email, Facebook, LinkedIn, Twitter, etc. A wide selection of journals (inclusive of 9 subjects, more than 200 journals) Providing 24-hour high-quality service

User-friendly online submission system

Fair and swift peer-review system

Efficient typesetting and proofreading procedure

Display of the result of downloads and visits, as well as the number of cited articles Maximum dissemination of your research work

Submit your manuscript at: http://papersubmission.scirp.org/

Or contact ojpathology@scirp.org 